\title{
APLICAÇÃO DE MÉTODOS QUANTITATIVOS EM AUDITORIA: PROPOSTAS PARA OTIMIZAR PROCEDIMENTOS E REDUZIR RISCOS
}

\section{QUANTITATIVE METHODS APPLICATION ON AUDITING: PROPOSALS TO OPTIMIZE PROCEEDINGS AND REDUCE RISKS}

\author{
JOSELITO DE MACEDO RIBEIRO \\ Especialista em Administração de Empresas pela \\ Faculdade Estadual de Feira de Santana \\ E-mail: fsa@ftc.br
}

\author{
JOSE MARIA DIAS FILHO \\ Professor Doutor do Programa de Pós-graduação em \\ Contabilidade da Universidade Federal da Bahia \\ E-mail: zemariadias@uol.com.br
}

\section{Resumo}

0 presente trabalho tem como objetivo investigar a importância de aplicar técnicas estatísticas em atividades de auditoria, em adição a outros recursos quantitativos, para que o auditor independente possa executar procedimentos com mais segurança e emitir o seu parecer com o mínimo de risco possível. Parte-se do princípio de que a auditoria deve se apoiar em técnicas que viabilizem julgamentos mais adequados acerca da validade dos registros contábeis. Considera-se também a necessidade de recuperar a credibilidade dessa atividade, tão desgastada em função de escândalos financeiros que abalaram o mundo corporativo nos últimos anos, principalmente no cenário internacional. Por meio de um estudo de caso, a pesquisa procurou demonstrar que ferramentas estatísticas, tais como análise de regressão e correlação, podem ajudar, de forma relevante, o auditor a levantar indícios de erros e fraudes. Na organização investigada, verificou-se, por exemplo, falta de relacionamento significativo entre estoques e desembolsos de caixa. Constatações desse tipo ajudam o auditor a formular hipóteses sobre a origem dos recursos utilizados pela entidade e selecionar procedimentos com maior probabilidade de colher as evidências necessárias à fundamentação de seu parecer.

Palavras-chave: métodos quantitativos; auditoria; princípios de auditoria.

\begin{abstract}
The present work has as objective to investigate the importance of applying statistic techniques on auditing activities, summed up with other quantitative resources, so that the auditor can develop procedures with more security and pass his sentence with the less risk as possible. We start from the principle that auditing must be supported by techniques that make it feasible to judge the validity of accounting register in a more adequate way. It is also considered the necessity of recovering the credibility of this activity, which has been very consumed by financial scandals that have recently shocked corporative field, especially in international context. As in a case study, the research aimed to demonstrate that statistic tools, like regression and correlation analyses, can help the auditor to find traces of errors and frauds. On the studied Organization, it was verified, for example, the lack of significant relation between stock and cash disbursement. Observations like this one assist the auditor on hypothesis formulation about the origin of the entity utilized resources and on the selection of proceedings with higher probability to have the necessary evidences to support his sentence.
\end{abstract}

Key words: quantitative methods, auditing, auditing principles. 


\section{INTRODUÇÃO}

Como as atividades de auditoria se desenvolvem sob restrições de tempo e recursos financeiros, nem sempre o auditor independente pode realizar uma revisão integral dos registros e transações que busca representar. Em função disso, torna-se necessária a adoção de estratégias que contribuam para minimizar riscos de se emitir uma opinião inadequada acerca das demonstrações contábeis. Uma delas é a avaliação do sistema de controles internos da entidade, para determinar a natureza, oportunidade e extensão da aplicação dos procedimentos de auditoria. Tomam-se os controles internos como indicadores do grau de confiabilidade das demonstrações, já que se atribui a eles o papel de proteger os ativos da entidade contra erros e fraudes, além de promover o cumprimento das diretrizes administrativas. Parte-se do princípio de que quanto mais consistentes e adequados forem os controles mantidos pela entidade, maior a probabilidade de que as suas demonstrações contábeis reflitam a realidade que objetivam demonstrar. Esse esforço de avaliação inicial embute o risco de o auditor julgar que o sistema de controles internos é capaz de prevenir erros e fraudes em nível superior ao tolerável, quando na verdade isso não ocorre. Como minimizar esse tipo de risco por meio de recursos estatísticos? Esta é uma das questões que norteiam o desenvolvimento deste trabalho.

Cumprida a etapa de avaliação do sistema de controles internos, parte-se para a aplicação dos chamados testes substantivos. Com eles, busca-se colher evidências sobre o grau de fidedignidade das transações e registros contábeis. Aqui, mais uma vez, o auditor precisa se cercar de cuidados para realizar julgamentos adequados e minimizar os riscos de emitir uma opinião incorreta sobre as demonstrações contábeis. Tecnicamente, esse risco é definido como a possibilidade de o auditor ser induzido por seus exames à conclusão de inexistir erro em nível superior ao tolerável, quando na realidade esse fato ocorre. Temse, aqui, o chamado risco de detecção. Como minimizá-lo, é também questão que orienta o raciocínio adotado neste artigo. Que recursos podem ser utilizados pelo auditor, além daqueles já utilizados tradicionalmente para reduzir o risco de se concluir pela inexistência de um erro que de fato existe?

Acrescente-se a tais riscos, o chamado risco inerente, que diz respeito à possibilidade de ocorrer erro no saldo de uma conta, por inadequação ou, até mesmo, inexistência de controles internos. Como lidar com esse tipo de risco? Que tipo de recurso pode ser utilizado para preveni-lo, no campo da estatística?

Essas são algumas questões de que se ocupa o presente trabalho.

\section{A IMPORTÂNCIA DO ASSUNTO}

Os escândalos financeiros que abalaram o mundo corporativo nos últimos anos abalaram também a credibilidade de uma atividade vital ao funcionamento dos mercados de capitais, que é a auditoria. Em geral, considera-se que a contabilidade pode contribuir, significativamente, para reduzir a assimetria informacional, quer seja entre acionistas e administradores, quer seja entre os próprios acionistas majoritários e minoritários. Porém, sabe-se que ela não pode cumprir esse objetivo, satisfatoriamente, sem o apoio da auditoria. Afinal, na ausência dessa técnica, os números contábeis podem ser manipulados com mais facilidade, em prejuízo de determinados agentes. Mas a eficácia da auditoria depende de um atributo essencial: credibilidade. Sem credibilidade, o parecer do auditor 
não significa mais do que um conjunto de palavras destituídas do poder de influenciar comportamentos. $\mathrm{O}$ que fazer, então, para garantir a credibilidade da auditoria?

Preocupado com questões dessa natureza, recentemente o Conselho Federal de Contabilidade (CFC) aprovou normas estabelecendo procedimentos e critérios para planejar e selecionar amostra de itens a serem examinados pelo auditor. A Norma Brasileira de Contabilidade, NBC T 11.11 - Amostragem, aprovada pela Resolução CFC $n^{\circ}$ 1.012 de 21/1/2005, afirma, inclusive, que ao determinar a extensão de um teste de auditoria ou método de seleção de itens a testar, o auditor pode empregar técnicas de amostragem. Mas seria a amostragem o único recurso que pode ser utilizado em tais circunstâncias?

Apesar de muitos autores, como Boynton et all (2002) e Franco e Marra (2001) se referirem apenas à amostragem, o CFC estabelece que "é importante reconhecer que certos procedimentos de auditoria aplicados na base de testes não estão dentro da definição de amostragem..." e que "quando o erro projetado exceder o erro tolerável o auditor deve considerar a possibilidade de ampliar o procedimento de auditoria ou executar procedimentos de auditoria alternativos". Como se vê, abre-se a possibilidade de o auditor utilizar outros recursos de caráter complementar, além da amostragem, é claro.

De forma semelhante, o Instituto dos Auditores Independentes do Brasil (IBRACON), nas Normas de Procedimentos de Auditoria Independente de Instituições Financeiras e Entidades Equiparadas (NPA 02), ao se referir à técnica de amostragem, afirma que ao definir a extensão de seus testes de auditoria, o auditor poderá recorrer, ou não, a métodos estatísticos científicos. Novamente, percebe-se a preocupação dos órgãos normatizadores com a utilização de recursos que contribuam para aumentar a eficácia da auditoria. Considera-se, obviamente, 0 nível de responsabilidade que 0 auditor independente assume na emissão de seu parecer e, principalmente, os interesses das diversas camadas de usuários das informações contábeis.

Sabe-se que a estatística dispõe de muitos métodos que são utilizados com freqüência em diversos campos das ciências, e que se pode testar a utilidade deles em qualquer ramo profissional. Diante disso, e considerando as dificuldades por que passa a atividade de auditoria em todo o mundo, não seria o momento de reforçar as técnicas utilizadas pelo auditor em seus julgamentos? Ou, em outras palavras, por que não avaliar a conveniência de utilizar métodos estatísticos alternativos nas atividades de auditoria, além da amostragem, naturalmente? Esses questionamentos nos levam à formulação do problema central deste estudo: "além dos recursos empregados com mais freqüência, a exemplo da amostragem, que técnicas estatísticas poderiam ser utilizadas, em caráter complementar, para diminuir os riscos de auditoria?"

\section{FUNDAMENTAÇÃO TEÓRICA}

Considera-se que a contabilidade atua como poderoso instrumento de redução da assimetria informacional, contribuindo, assim, para minimizar conflitos de agência. Entende-se, inclusive, que nisto reside a sua principal finalidade, de forma que no modelo de empresa preconizado pela teoria da firma, o aparato contábil não teria serventia. É no mundo complexo, marcado por conflitos de interesse, que ela ganha relevância. 0 caso da empresa norte-americana Enron pode ser utilizado, mais uma vez, para ilustrar a importância de instrumentos que minimizem riscos decorrentes de conflitos de agência.

Considera-se também, que a contabilidade tem capacidade de orientar os seus usuários rumo a decisões de melhor qualidade, dependendo da validade dos dados que ela 
possa fornecer. É exatamente para aferir o grau de fidedignidade das demonstrações contábeis que se utiliza a auditoria. Assim, importa verificar se essa atividade se desenvolve sob critérios que the permitam fazer julgamentos adequados sobre os números contábeis. Em outras palavras, não basta submeter as demonstrações contábeis a este ou àquele procedimento de verificação. Mais do que isso, é preciso ter garantiras de que as técnicas de verificação permitem ao auditor enxergar a verdade que às vezes se deseja ocultar. Sem isso, a eficácia desse aparato pode ficar seriamente comprometida.

Ciente dessa realidade, geralmente recomenda-se a utilização de métodos estatísticos para auxiliar o auditor em suas investigações. Porém, visitando a literatura especializada, nota-se que a alusão a tais métodos concentra-se basicamente na técnica de amostragem. Salienta-se que, mediante esse exame, pode-se inferir sobre a qualidade de um universo sem examinar todos os seus componentes desde quando a abrangência seja representativa, quer quanto à relevância dos valores envolvidos ou quanto à natureza dos itens objeto do exame (Resolução CFC n 607/85).

Em regra, não se considera que a estatística apresente ferramentas adicionais que possam contribuir, de forma relevante, no julgamento das demonstrações financeiras das empresas. É importante esclarecer que não se trata aqui de questionar a validade de métodos tradicionais, mas apenas alertar para a conveniência de empregar outros recursos que poderiam agregar mais qualidade aos trabalhos de auditoria. Afinal, o potencial da auditoria e o seu campo de aplicação são bastante amplos, como bem salientam Anderson, Sweeney e Williams (2002, pg. 19). Como não se tem evidência empírica de que os recursos mais utilizados são suficientes para diminuir o risco de auditoria, este trabalho vem propor a utilização de métodos estatísticos alternativos de caráter complementar. Pretende-se, pois, oferecer uma contribuição para que o auditor torne-se mais equipado tecnicamente no desenvolvimento de suas atividades.

Conforme salientamos, ultimamente tem-se questionado muito a qualidade dos trabalhos de auditoria em função de escândalos que envolveram grandes corporações, como Enron e WorldCom. Aliás, surge desse contexto a Lei Sarbanes-Oxley, impondo novas exigências para o processo de verificação das demonstrações contábeis, entre as quais é digna de menção a constituição de um Comitê de Auditoria para acompanhar a atuação dos auditores. Uma das atribuições desse Comitê é justamente aprovar os serviços de auditoria. Note-se, por aí, que novas exigências tendem a recair sobre os auditores no tocante à qualidade dos trabalhos que vêm executando. Se o conhecimento estatístico contribui em diversas áreas, tais como economia, administração, direito, odontologia, medicina entre outras, provavelmente tenha muito a oferecer também aos profissionais da área contábil e, particularmente, àqueles que atuam no campo da auditoria.

Outro elemento que nos parece importante explorar sob a perspectiva da literatura corrente, é a relação entre risco e controles internos. De início, lembramos que o termo risco, em auditoria, é utilizado para expressar a possibilidade do auditor emitir uma opinião inadequada sobre as demonstrações contábeis quando elas não refletem adequadamente a realidade. Segundo Francis (2004), o correto dimensionamento do risco deve se iniciar justamente pela avaliação do sistema de controles internos mantidos pela empresa, entendido como o conjunto de medidas tendentes a proteger os ativos contra erros e fraudes, bem como promover a eficiência operacional. Conforme se destaca nas normas de auditoria, essa providência é necessária para que o auditor possa determinar a natureza e a extensão dos exames e, ainda, o momento em que devem ser aplicados.

Porém, no dimensionamento de riscos deve-se considerar que as medidas de controle apresentam certas limitações e, portanto, não devem ser interpretadas como garantia absoluta de qualidade, mas sim como um indicador do grau de credibilidade que pode ser atribuído às demonstrações contábeis. É preciso compreender, por exemplo, que o controle tende a ser mais eficaz quando engendrado dentro da infra-estrutura da 
organização e a ela se incorpora de maneira mais natural, sem o peso da imposição formal (PESQUEUX, 2005). Isso pressupõe, como se pode depreender uma "cultura de controles", em que todos os sujeitos envolvidos visualizem as medidas de controle como elementos naturais, integrados aos processos operacionais do cotidiano.

A auditoria, no novo cenário da Governança Corporativa, deve considerar também que os controles internos são implementados essencialmente por pessoas e isso, por si só, já exige alguns cuidados adicionais para garantir a sua eficácia. Assim, avaliar controles e dimensionar riscos exige do auditor mais do que uma simples verificação da existência de normas e procedimentos formalmente estabelecidos (PETTERSON, 2005). Antes de tudo, é preciso observar se todos os integrantes do sistema estão suficientemente esclarecidos acerca dos objetivos do sistema de controles e comprometidos com a sua observância. Deve-se considerar, enfim, que os controles afetam as ações e o comportamento dos indivíduos e até mesmo as suas expectativas individuais, o que pode restringir a eficácia das medidas (VORHIE, 2005).

No dimensionamento de riscos a que fica exposta a auditoria, atenção especial deve ser dada aos problemas de agenciamento. Com a separação entre propriedade e gestão, há de se considerar que nem sempre os elementos incumbidos de executar os planos estão dispostos a cumprir normas e agir de acordo com as expectativas dos proprietários. Se adotarmos a premissa de que o homem atua buscando a maximização de seu próprio bemestar, conforme preconiza a teoria microeconômica clássica, não se pode desprezar a possibilidade de haver certo descolamento entre o idealizado pelos proprietários do negócio e o realizado pelos administradores. A literatura especializada sugere que esse é um dos problemas que devem ser considerados em qualquer sistema de monitoramento, entre os quais se insere a auditoria (FAMÁ e JENSEN, 1998).

De acordo com Jensen (1998), um dos principais instrumentos de que as organizações dispõem para verificar se as suas atividades se desenrolam conforme as diretrizes estabelecidas pela Governança é justamente a auditoria. Entretanto, o histórico de escândalos financeiros e tantos outros eventos que acabam afetando os interesses de acionistas sugerem que para ser eficaz esse mecanismo de monitoramento deve ser aprimorado constantemente. Um exemplo de melhoria nessa área é a já mencionada Lei Sarbanes-Oxley, que repercute em todo o mundo pela tentativa de elevar o nível de trabalho do auditor e obrigar a administração a reforçar seus controles internos, agravando as conseqüências para comportamentos antiéticos ou ilegais.

Para Boynton, Johnson e Kell (2002, pg. 181), o desafio último da auditoria consiste no fato de que os auditores não podem examinar todas as possíveis evidências referentes a todas as afirmações e saldos de contas ou classes de transações. 0 modelo de risco de auditoria orienta auditores na coleta dessas evidências, para que eles possam atingir o desejado grau de segurança razoável. 0 auditor deve considerar risco de auditoria não somente para cada saldo de conta e classe de transações, mas também para cada afirmação relevante sobre os saldos materiais.

\section{ASPECTOS METODOLÓGICOS}

Conforme se mencionou anteriormente, o objetivo principal desta pesquisa é apresentar métodos estatísticos que possam ser utilizados pelo auditor ao lado de outras técnicas convencionais, como instrumentos de apoio à execução de seus trabalhos e à formação de uma opinião mais segura sobre a fidedignidade das demonstrações contábeis. Para tanto, elegeu-se como objeto de investigação as demonstrações contábeis de uma empresa do setor metalúrgico, que, por razões de ética e sigilo profissional, doravante 
será identificada como JMR.

A escolha dessa empresa foi feita através do método não probabilístico, utilizandose da técnica de amostragem de conveniência que, segundo Anderson et all (2002), é uma técnica pela qual os elementos são incluídos na amostra sem probabilidades préespecificadas ou conhecidas.

Também por conveniência, tomaram-se como base os exercícios de 2003 e de 2004 da JMR, para análise dos lançamentos diários em dois meses das contas selecionadas. Já para a escolha dos meses, utilizou-se a técnica da amostragem sistemática (AS), que é o processo de escolha de elementos de uma população conhecida $N$, através de amostragem aleatória simples (AAS). Uma amostra sistemática de tamanho $n$ é constituída dos elementos de ordem $K, K+r, K+2 r, \ldots$, em que $r=\frac{N}{n}$ e $K$ é um inteiro escolhido aleatoriamente através de uma Tabela de Números Aleatórios (TNA) entre " 0 " e a razão $r$. Com o apoio dessa tabela, gerada através do excel, foram adotados os procedimentos complementares.

Precisamente, o trabalho busca explorar possíveis relações entre os seguintes pares: "caixa e vendas"; "duplicatas a receber e vendas a prazo"; "estoques e saídas de caixa". A seleção dessas contas foi guiada pela aplicação de questionário, para identificar as rubricas que se constituem em alvo preferencial dos auditores no planejamento e execução dos trabalhos. Foram distribuídos 100 questionários a auditores, por meio eletrônico (email) e pessoalmente, dos quais 31 foram respondidos. Como o trabalho não tinha pretensão de formular generalizações acerca das contas que costumam receber maior atenção dos auditores, mas apenas se ancorar em alguma referência sobre prioridades de investigação, considerou-se satisfatório o número de respondentes. No final desta seção, serão fornecidos esclarecimentos adicionais sobre o processo de seleção das contas supracitadas e os resultados obtidos nessa pesquisa. trabalho.

0 organograma apresentado na Figura 1 oferece uma visão estrutural de todo o 
Figura 1: Organograma da pesquisa

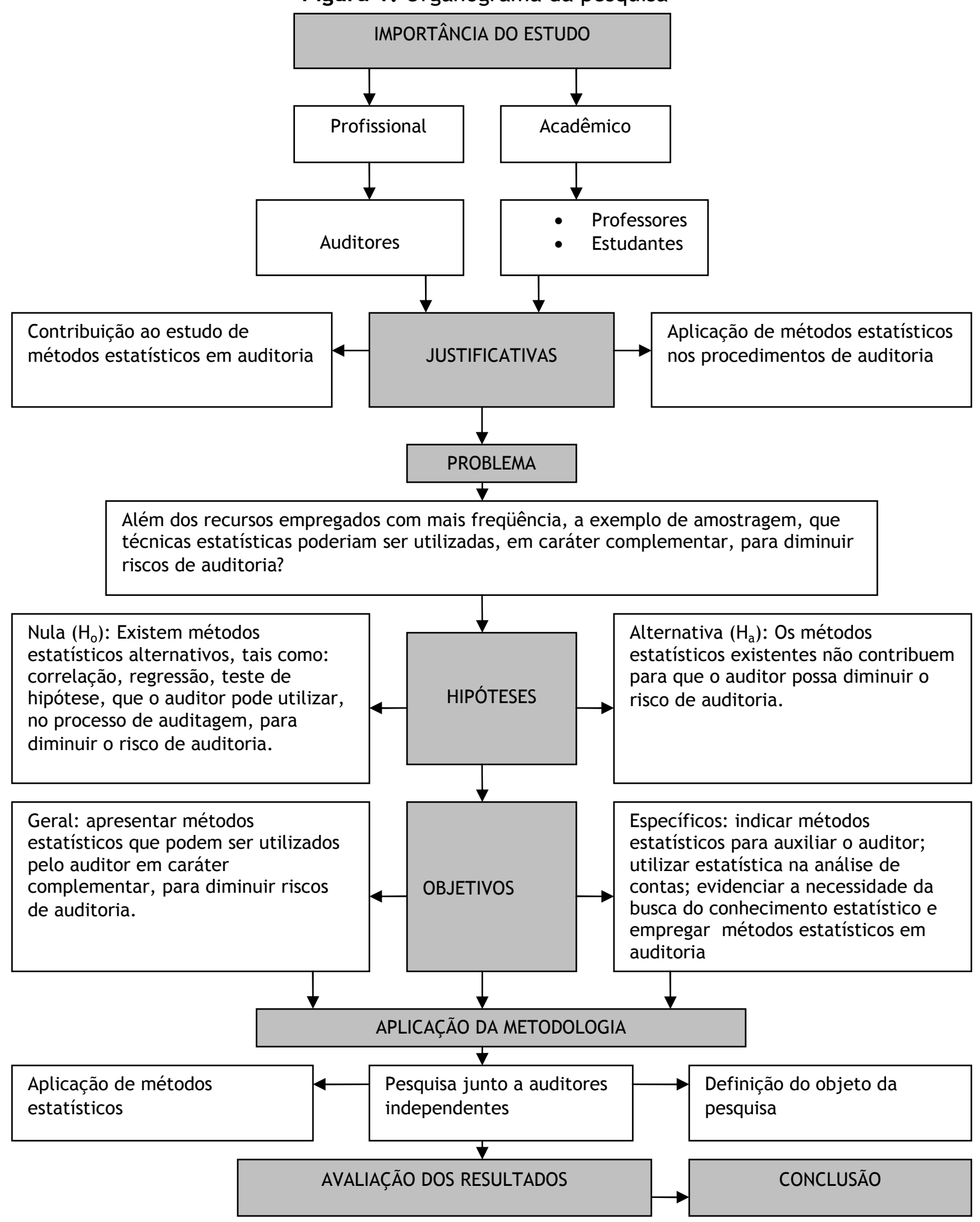

FONTE: Adaptado de Pereira, 2002. 


\section{4 - DADOS OBTIDOS NA PESQUISA}

Para melhor compreensão dos motivos pelos quais elegemos as contas "caixa", "contas a receber" e "estoques", apresenta-se um quadro-resumo das respostas fornecidas.

Quadro 1: Resultados obtidos na pesquisa

\begin{tabular}{|c|c|c|c|c|c|c|c|c|c|c|c|c|c|c|}
\hline \multirow{2}{*}{ OPÇÕES } & \multicolumn{14}{|c|}{ QUESTÕES } \\
\hline & 1 & 2 & 3 & 4 & 5 & 6 & 7 & 8 & 9 & 10 & 11 & 12 & 13 & 14 \\
\hline A & 277 & 293 & 255 & 252 & 247 & 226 & 225 & 279 & 276 & 255 & 279 & 283 & 265 & 285 \\
\hline B & 228 & 226 & 252 & 250 & 255 & 245 & 219 & 270 & 268 & 239 & 229 & 224 & 285 & 289 \\
\hline C & 205 & 215 & 262 & 236 & 242 & 242 & 221 & 287 & 253 & 241 & 287 & 210 & 256 & 262 \\
\hline D & 220 & 223 & 270 & 248 & 239 & 240 & 242 & 256 & 238 & 237 & 212 & 255 & 268 & 264 \\
\hline$E$ & 197 & 194 & 197 & 197 & & 208 & 215 & 225 & 222 & 245 & 199 & 215 & 214 & 208 \\
\hline $\mathrm{F}$ & & 286 & & & & & & & & & 248 & 218 & 255 & 267 \\
\hline$G$ & & 229 & & & & & & & & & 225 & & 213 & 215 \\
\hline $\mathrm{H}$ & & 192 & & & & & & & & & 211 & & 265 & 253 \\
\hline $\mathrm{I}$ & & 223 & & & & & & & & & & & & \\
\hline
\end{tabular}

FONTE: Elaborado pelo(s) autor(es).

Cada letra da coluna “opções" representa alternativas vinculadas ao questionário da pesquisa. Por exemplo, a opção "a" da questão 1 diz respeito ao Balanço Patrimonial. Os resultados indicam que os auditores atribuem maior importância a essa peça por considerar que entre as demais é a que frequentemente está em desacordo com as normas de contabilidade. A opção "a" da questão 2 diz respeito ao grupo do Ativo Circulante. Os resultados indicam que os auditores atribuem maior importância a esse grupo na aplicação dos procedimentos de auditoria. De igual forma, o quadro indica que os auditores priorizam as contas "caixa", "duplicatas a receber" e "estoques", as quais correspondem, respectivamente, às opções "a", "c" e "d" da questão 3. Nesse sentido, resolveu-se trabalhar com essas contas, para tentar identificar possíveis relacionamentos e, assim, demonstrar a importância do uso de métodos quantitativos em auditoria.

Aliás, oportunamente, destaque-se que dos 31 auditores respondentes, 22 se declararam usuários de métodos estatísticos, ao passo que nove afirmaram o contrário (que não aplicam métodos quantitativos em procedimentos de auditoria).

Sobre os métodos que utilizam, 16 auditores responderam que recorrem à amostragem; cinco não especificaram os métodos utilizados; e um respondeu que utiliza ponderação de riscos. A partir dessas informações, iniciou-se a coleta de dados nas contas "caixa", "duplicatas a receber" e "estoques" da empresa JMR. 


\section{4 - ANÁLISE DOS DADOS}

O quadro 2 apresenta um comparativo do caixa com as vendas à vista.

Quadro 2: Comparativo do caixa com vendas à vista

\begin{tabular}{|c|r|r|r|r|r|}
\hline \multicolumn{3}{|c|}{ OUTUBRO DE 2003} & \multicolumn{3}{c|}{ OUTUBRO DE 2004 } \\
\hline DIA & ENTRADAS & VDA A VISTA & DIA & ENTRADAS & VDA A VISTA \\
\hline 1 & $10.979,80$ & $5.202,10$ & 1 & $20.609,13$ & $20.379,15$ \\
\hline 2 & $11.510,23$ & $7.230,40$ & 2 & $5.249,52$ & $5.249,52$ \\
\hline 3 & $3.141,53$ & $3.075,53$ & 4 & $13.415,08$ & $7.780,08$ \\
\hline 4 & $2.101,57$ & $2.101,57$ & 5 & $8.445,43$ & $7.674,43$ \\
\hline 6 & $10.959,13$ & $10.805,13$ & 6 & $5.510,76$ & $4.787,19$ \\
\hline 7 & $8.874,88$ & $7.859,88$ & 7 & $2.530,32$ & $2.261,42$ \\
\hline 8 & $4.283,14$ & $4.148,14$ & 8 & $5.417,30$ & $5.417,30$ \\
\hline 9 & $9.343,17$ & $8.983,17$ & 9 & $8.244,80$ & $6.465,98$ \\
\hline 10 & $4.932,02$ & $4.932,02$ & 11 & $14.485,51$ & $11.776,71$ \\
\hline 11 & $7.921,85$ & $7.891,85$ & 12 & $1.486,70$ & $1.486,70$ \\
\hline 13 & $19.927,32$ & $11.608,60$ & 13 & $6.338,81$ & $3.281,81$ \\
\hline 14 & $5.993,72$ & $5.266,72$ & 14 & $10.764,77$ & $10.764,77$ \\
\hline 15 & $6.026,37$ & $2.579,62$ & 15 & $9.489,86$ & $9.288,00$ \\
\hline 16 & $7.417,65$ & $4.930,65$ & 16 & $1.403,04$ & $1.403,04$ \\
\hline 17 & $3.761,55$ & $2.854,55$ & 19 & $3.621,11$ & $3.621,31$ \\
\hline 18 & $12.233,99$ & $12.233,99$ & 20 & $14.582,31$ & $14.227,13$ \\
\hline 20 & $1.166,00$ & 0,00 & 21 & $4.833,54$ & $4.833,54$ \\
\hline 21 & $16.583,89$ & $3.897,14$ & 22 & $15.770,45$ & $15.694,53$ \\
\hline 22 & $7.888,94$ & $7.613,94$ & 23 & $8.029,97$ & $2.842,74$ \\
\hline 23 & $11.353,73$ & $11.353,73$ & 25 & $4.129,90$ & $4.129,90$ \\
\hline 24 & $3.585,06$ & $2.302,73$ & 26 & $9.313,58$ & $9.313,58$ \\
\hline 25 & $2.289,78$ & $2.289,78$ & 27 & $3.234,35$ & $3.234,35$ \\
\hline 27 & $9.856,84$ & $7.480,84$ & 28 & $2.311,89$ & $2.311,89$ \\
\hline 28 & $8.216,13$ & $7.732,46$ & 29 & $1.875,59$ & $1.875,59$ \\
\hline 29 & $7.509,93$ & $6.909,93$ & 30 & $3.004,17$ & $3.004,17$ \\
\hline 30 & $9.647,78$ & $9.707,78$ & & & \\
\hline 31 & $4.300,70$ & $2.533,70$ & & & $163.104,83$ \\
\hline$\Sigma$ & $211.808,70$ & 163525,95 & & $184.097,89$ & \\
\hline
\end{tabular}

FONTE: Elaborado pelo(s) autor(es).

Entre outros procedimentos de natureza estatística, procurou-se estimar o grau de relação e explicação entre as variáveis caixa e vendas à vista, através da análise de regressão. Com aplicação do software SPPS, obtiveram-se os resultados apresentados nos Quadros 3, 4, 5 e 6. 
Quadro 3: Variáveis de entrada

Variables Entered/Removed

\begin{tabular}{|l|c|c|c|}
\hline Model & $\begin{array}{c}\text { Variables } \\
\text { Entered }\end{array}$ & $\begin{array}{c}\text { Variables } \\
\text { Removed }\end{array}$ & Method \\
\hline 1 & VENDAS $^{2}$ & & Enter \\
\hline
\end{tabular}

a. All requested variables entered.

b. Dependent Variable: CAIXA

Quadro 4: Resumo do modelo

Model Summary

\begin{tabular}{|l|r|r|r|r|}
\hline Model & $\mathrm{R}$ & R Square & $\begin{array}{c}\text { Adjusted } \\
\text { R Square }\end{array}$ & $\begin{array}{c}\text { Std. Error of } \\
\text { the Estimate }\end{array}$ \\
\hline 1 &, $858^{\mathrm{a}}$ &, 736 &, 730 & $* \star * \star * \star * \star *$ \\
\hline
\end{tabular}

a. Predictors: (Constant), VENDAS

FONTE: Elaborado através do SPSS.

Quadro 5: Análise da variância

ANOVA

\begin{tabular}{|c|c|c|c|c|c|c|}
\hline Model & & $\begin{array}{l}\text { Sum of } \\
\text { Squares }\end{array}$ & $d f$ & Mean Square & $\mathrm{F}$ & Sig. \\
\hline \multirow[t]{3}{*}{1} & Regression & $8,41 E+08$ & 1 & 841156303,9 & 139,163 &, $000^{\mathrm{a}}$ \\
\hline & Residual & $3,02 E+08$ & 50 & 6044383,784 & & \\
\hline & Total & $1,14 \mathrm{E}+09$ & 51 & & & \\
\hline
\end{tabular}

a. Predictors: (Constant), VENDAS

b. Dependent Variable: CAIXA

Quadro 6: Coeficientes da equação da reta de regressão

Coefficients $^{\mathrm{a}}$

\begin{tabular}{|c|c|c|c|c|c|c|}
\hline \multirow{2}{*}{\multicolumn{2}{|c|}{ Model }} & \multicolumn{2}{|c|}{$\begin{array}{c}\text { Unstandardized } \\
\text { Coefficients }\end{array}$} & \multirow{2}{*}{$\begin{array}{c}\begin{array}{c}\text { Standardi } \\
\text { zed }\end{array} \\
\begin{array}{c}\text { Coefficien } \\
\text { ts }\end{array} \\
\text { Beta }\end{array}$} & \multirow[b]{2}{*}{$\mathrm{t}$} & \multirow[b]{2}{*}{ Sig. } \\
\hline & & B & Std. Error & & & \\
\hline & (Constant) & 1456,023 & 623,449 & & 2,335 &, 024 \\
\hline & VENDAS &, 980 &, 083 & ,858 & 11,797 & ,000 \\
\hline
\end{tabular}

a. Dependent Variable: CAIXA

FONTE: Quadros elaborados através do SPSS. 
Dos resultados apresentados, pode-se chegar às seguintes conclusões:

a) 0 valor estimado de numerário no caixa é dado pela equação da reta de regressão $\hat{Y}=a+b X$. Assim, $\hat{Y}=1.456,02+0,98 X$;

b) quando a venda $(\mathrm{X})$ aumenta de uma unidade; o caixa $(\mathrm{Y})$ sofre um acréscimo médio de $\mathrm{R} \$ \mathbf{0 , 9 8}$

c) o $r$ múltiplo ou coeficiente de correlação 0,858 indica que é alta a relação entre as duas variáveis; e

d) o $r^{2}$ ou coeficiente de explicação 0,736 indica que 73,6\% dos valores ingressos no caixa são explicados pela variação das vendas.

Qual é a utilidade desses resultados para o serviço de auditoria? Como apenas 73,6\% dos valores incorporados ao caixa pode ser explicado por vendas à vista; o auditor deverá investigar a procedência da parte complementar, ou seja, os $26,4 \%$ dos valores debitados na conta caixa. Nota-se, portanto, que não há uma perfeita relação entre os valores de vendas e os numerários registrados no caixa. Essa é uma informação relevante, inclusive, para a definição do escopo dos trabalhos de auditoria.

O Quadro 7 apresenta um comparativo entre as contas de estoques e as saídas do

Quadro 7 - Comparativo entre as contas estoques e saídas do caixa

\begin{tabular}{|c|c|c|c|c|c|}
\hline \multicolumn{3}{|c|}{ OUTUBRO DE 2003} & \multicolumn{3}{c|}{ OUTUBRO DE 2004 } \\
\hline DIA & ENTRADAS & PAGAMENTOS & DIA & ENTRADAS & PAGAMENTOS \\
\hline 1 & $19.081,97$ & $17.274,27$ & 1 & $22.053,20$ & $2.011,12$ \\
\hline 2 & $20.263,38$ & $11.831,96$ & 2 & 660,13 & 440,00 \\
\hline 3 & $3.928,75$ & $6.468,26$ & 4 & $22.096,95$ & $5.617,50$ \\
\hline 6 & $2.725,01$ & $20.058,78$ & 5 & $8.293,33$ & $19.398,65$ \\
\hline 7 & $2.006,32$ & $1.209,33$ & 6 & $3.794,54$ & $4.005,33$ \\
\hline 8 & $6.532,31$ & $1.111,01$ & 7 & 777,95 & 511,28 \\
\hline 9 & $51.304,58$ & 913,42 & 8 & $16.533,34$ & $12.291,29$ \\
\hline 10 & $2.172,45$ & $15.678,95$ & 9 & $8.043,98$ & $6.883,48$ \\
\hline 11 & $9.254,99$ & 0 & 11 & $12.119,12$ & $20.595,50$ \\
\hline 13 & 208,00 & $12.654,83$ & 13 & 924,26 & $8.599,02$ \\
\hline 14 & $5.773,42$ & $22.352,27$ & 14 & $8.897,38$ & $13.659,73$ \\
\hline 15 & $2.483,57$ & $13.541,84$ & 15 & $10.789,65$ & $20.178,11$ \\
\hline 16 & $13.923,04$ & $7.947,03$ & 19 & $14.078,94$ & $10.262,16$ \\
\hline 21 & $6.465,09$ & $5.694,02$ & 20 & $7.616,67$ & 992,56 \\
\hline 22 & 710,50 & $22.687,27$ & 21 & $16.675,68$ & $14.151,59$ \\
\hline 23 & $5.800,55$ & 278,53 & 22 & $6.739,64$ & $5.287,32$ \\
\hline 24 & $8.951,99$ & $5.711,54$ & 23 & $8.905,36$ & $9.614,23$ \\
\hline 25 & $12.784,87$ & $2.772,39$ & 25 & $11.199,66$ & $6.497,37$ \\
\hline 27 & $8.283,87$ & $3.853,48$ & 26 & $1.662,56$ & $5.015,65$ \\
\hline 28 & $13.746,30$ & $4.588,84$ & 27 & $2.077,10$ & $4.661,73$ \\
\hline 29 & $13.931,41$ & $7.557,77$ & 28 & $13.971,82$ & $6.519,10$ \\
\hline 30 & $8.863,10$ & $14.389,24$ & 29 & $16.454,60$ & $8.666,64$ \\
\hline 31 & $26.035,50$ & $14.546,61$ & & & \\
\hline$\Sigma$ & $245.230,97$ & $227.538,80$ & & $214.365,86$ & $185.859,36$ \\
\hline & & & & & \\
\hline
\end{tabular}

Seguindo o mesmo critério adotado no item anterior, procurou-se estimar o grau de relação e explicação entre as variáveis estoques e saídas de caixa, através da análise de regressão. Também com o apoio do software SPPS, obtiveram-se os resultados apresentados nos Quadros 8, 9, 10 e 11: 
Quadro 8: Variáveis de entrada

Variables Entered/Removed

\begin{tabular}{|l|l|l|l|}
\hline Model & $\begin{array}{l}\text { Variables } \\
\text { Entered }\end{array}$ & $\begin{array}{c}\text { Variables } \\
\text { Removed }\end{array}$ & Method \\
\hline 1 & $\begin{array}{l}\text { PAGAMEN } \\
\text { TO }\end{array}$ & & Enter \\
\hline
\end{tabular}

a. All requested variables entered.

b. Dependent Variable: ESTOQUE

Quadro 9: Resumo do modelo

Model Summary

\begin{tabular}{|l|r|r|r|r|}
\hline Model & $\mathrm{R}$ & R Square & $\begin{array}{c}\text { Adjusted } \\
\text { R Square }\end{array}$ & $\begin{array}{c}\text { Std. Error of } \\
\text { the Estimate }\end{array}$ \\
\hline 1 &, $066^{\mathrm{a}}$ &, 004 &,- 019 & ${ }^{\star \star \star \star \star \star \star \star \star \star}$ \\
\hline
\end{tabular}

a. Predictors: (Constant), PAGAMENTO

Quadro 10: Análise da variância

ANOVAb

\begin{tabular}{|c|c|c|c|c|c|c|}
\hline Model & & $\begin{array}{l}\text { Sum of } \\
\text { Squares }\end{array}$ & df & Mean Square & $\mathrm{F}$ & Sig. \\
\hline \multirow[t]{3}{*}{1} & Regression & 16011674 & 1 & 16011673,93 & , 190 &, $665^{a}$ \\
\hline & Residual & $3,62 E+09$ & 43 & 84082357,00 & & \\
\hline & Total & $3,63 E+09$ & 44 & & & \\
\hline
\end{tabular}

a. Predictors: (Constant), PAGAMENTO

b. Dependent Variable: ESTOQUE

Quadro 11: Coeficientes da equação da reta de regressão

Coefficients $^{\mathrm{a}}$

\begin{tabular}{|c|c|c|c|c|c|c|}
\hline \multirow{2}{*}{\multicolumn{2}{|c|}{ Model }} & \multicolumn{2}{|c|}{$\begin{array}{c}\text { Unstandardized } \\
\text { Coefficients }\end{array}$} & \multirow{2}{*}{$\begin{array}{c}\begin{array}{c}\text { Standardi } \\
\text { zed } \\
\text { Coefficien } \\
\text { ts }\end{array} \\
\text { Beta }\end{array}$} & \multirow[b]{2}{*}{$\mathrm{t}$} & \multirow[b]{2}{*}{ Sig. } \\
\hline & & $\mathrm{B}$ & Std. Error & & & \\
\hline & (Constant) & 11016,188 & 2292,153 & & 4,806 &, 000 \\
\hline & PAGAMENTO & $-9,06 \mathrm{E}-02$ & ,208 &,- 066 &,- 436 & ,665 \\
\hline
\end{tabular}

a. Dependent Variable: ESTOQUE

FONTE: Quadros elaborados através do SPSS.

Dos resultados expostos acima, pode-se chegar às seguintes conclusões:

a) 0 valor estimado do estoque, na saída de valores do caixa, é dado pela equação da reta: $\hat{Y}=11.016,20-0,09 X$; 
b) quando a saída do caixa $(\mathrm{X})$ diminui de uma unidade monetária; o estoque $(\mathrm{Y})$ diminui $\mathrm{R} \$ 0,09$;

c) o coeficiente de correlação 0,066 indica que praticamente não há relação entre as saídas de caixa e a aquisição de mercadorias; e

d) o coeficiente de explicação 0,004 também demonstra que a variação do estoque não é explicada pela variação ocorrida nas saídas de numerário do caixa.

Como se pode observar, a análise de regressão sugere que não existe relação significativa entre o volume de recursos aplicados em estoques e os desembolsos de caixa. Como a variável independente (pagamento) não pode ser utilizada como estimador da variável dependente (estoques), cabe ao auditor reforçar os procedimentos tendentes, para identificar as origens dos recursos que estão sendo utilizados em face da aquisição de mercadorias. Nesse caso, uma das hipóteses que se pode levantar é que a empresa lança mão de recursos não registrados contabilmente para honrar suas obrigações. Pode-se, ainda, trabalhar com a hipótese de que tais recursos resultam da venda de mercadorias tributáveis que deixaram de ser registradas para minimizar custos tributários. São hipóteses que merecem ser consideradas pelo auditor no processo de investigação.

O Quadro 12 apresenta um comparativo entre as duplicatas a receber e as vendas a prazo.

Quadro 12: Comparativo entre duplicatas a receber e vendas a prazo

\begin{tabular}{|c|c|c|c|c|c|}
\hline \multicolumn{3}{|c|}{ OUTUBRO DE 2003 } & \multicolumn{3}{c|}{ OUTUBRO DE 2004 } \\
\hline DIA & DUPLICATAS & V. A PRAZO & DIA & DUPLICATAS & V. A PRAZO \\
\hline 1 & $1.818,90$ & $1.818,90$ & 1 & $10.663,67$ & $10.663,67$ \\
\hline 2 & $2.222,22$ & $2.222,22$ & 2 & 814,92 & 814,92 \\
\hline 3 & 215,68 & 215,68 & 4 & $14.108,36$ & $14.108,36$ \\
\hline 4 & 497,28 & 497,28 & 5 & 861,43 & 861,43 \\
\hline 6 & $1.691,50$ & $1.691,50$ & 6 & $3.011,04$ & $3.011,04$ \\
\hline 7 & $4.215,82$ & $4.215,82$ & 7 & 890,00 & 890,00 \\
\hline 8 & $6.818,75$ & $6.818,75$ & 8 & $1.465,30$ & $1.465,30$ \\
\hline 9 & $1.446,59$ & $1.446,59$ & 9 & 437,67 & 437,67 \\
\hline 10 & 530,00 & 530,00 & 11 & $3.719,82$ & $3.719,82$ \\
\hline 11 & $2.752,40$ & $2.752,40$ & 12 & $1.181,40$ & $1.181,40$ \\
\hline 13 & $8.345,62$ & $8.345,62$ & 13 & 0 & 0 \\
\hline 14 & $6.488,80$ & $6.488,80$ & 14 & 774,32 & 774,32 \\
\hline 15 & $3.696,16$ & $3.696,16$ & 15 & $1.701,57$ & $1.701,57$ \\
\hline 16 & $1.178,97$ & $1.178,97$ & 19 & 0 & 0 \\
\hline 17 & $3.142,87$ & $3.142,87$ & 20 & 0 & 0 \\
\hline 21 & $5.358,27$ & $5.358,27$ & 21 & 296,00 & 296,00 \\
\hline 22 & $5.876,28$ & $5.876,28$ & 22 & 40,00 & 40,00 \\
\hline 23 & $4.056,24$ & $4.056,24$ & 23 & 0 & 0 \\
\hline 24 & $2.420,31$ & $2.420,31$ & 25 & 520,00 & 520,00 \\
\hline 25 & $1.744,12$ & $1.744,12$ & 26 & 0 & 0 \\
\hline 27 & $8.881,35$ & $8.881,35$ & 27 & 0 & 0 \\
\hline 28 & $2.630,74$ & $2.630,74$ & 29 & 579,00 & 579,00 \\
\hline 29 & $3.375,39$ & $3.375,39$ & & & \\
\hline 30 & $7.486,07$ & $7.486,07$ & & & \\
\hline 31 & $2.212,79$ & $2.212,79$ & & & $41.064,50$ \\
\hline$\Sigma$ & $89.103,12$ & $89.103,12$ & & $41.064,50$ & \\
\hline & & & & & \\
\hline
\end{tabular}

Em exemplo ao que se fez nos itens anteriores, buscou-se identificar o grau de explicação e correlação entre as variáveis duplicatas a receber e vendas a prazo. Com 
apoio do software SPSS, obtiveram-se os resultados apresentados nos Quadros 13, 14, 153 16:

Quadro 13: Variáveis de entrada

Variables Entered/Removed

\begin{tabular}{|l|c|c|c|}
\hline Model & $\begin{array}{c}\text { Variables } \\
\text { Entered }\end{array}$ & $\begin{array}{c}\text { Variables } \\
\text { Removed }\end{array}$ & Method \\
\hline 1 & VENDAS $^{\mathrm{a}}$ & & Enter \\
\hline
\end{tabular}

a. All requested variables entered.

b. Dependent Variable: DUPL

Quadro 14: Resumo do modelo

Model Summary

\begin{tabular}{|l|l|r|r|r|}
\hline Model & $\mathrm{R}$ & R Square & $\begin{array}{c}\text { Adjusted } \\
\text { R Square }\end{array}$ & $\begin{array}{r}\text { Std. Error of } \\
\text { the Estimate }\end{array}$ \\
\hline 1 & $1,000^{\mathrm{a}}$ & 1,000 & 1,000 &, 0000 \\
\hline
\end{tabular}

a. Predictors: (Constant), VENDAS

Quadro 15: Análise da variância

ANOVA

\begin{tabular}{|c|c|c|c|c|c|c|}
\hline \multicolumn{2}{|c|}{ Model } & $\begin{array}{l}\text { Sum of } \\
\text { Squares }\end{array}$ & $\mathrm{df}$ & Mean Square & $\mathrm{F}$ & Sig. \\
\hline \multirow[t]{3}{*}{1} & Regression & $4,02 E+08$ & 1 & 401553957,6 & , &,$^{a}$ \\
\hline & Residual &, 000 & 39 & ,000 & & \\
\hline & Total & $4,02 E+08$ & 40 & & & \\
\hline
\end{tabular}

a. Predictors: (Constant), VENDAS

b. Dependent Variable: DUPL

Quadro 16: Coeficientes da equação da reta de regressão

Coefficients $^{\mathrm{a}}$

\begin{tabular}{|c|c|c|c|c|c|}
\hline \multirow[b]{2}{*}{ Model } & \multicolumn{2}{|c|}{$\begin{array}{l}\text { Unstandardized } \\
\text { Coefficients }\end{array}$} & \multirow{2}{*}{$\begin{array}{c}\text { Standardi } \\
\text { zed } \\
\text { Coefficien } \\
\text { ts }\end{array}$} & \multirow[b]{2}{*}{$\mathrm{t}$} & \multirow[b]{2}{*}{ Sig. } \\
\hline & $\mathrm{B}$ & Std. Error & & & \\
\hline $\begin{array}{ll}1 & \text { (Constant) } \\
& \text { VENDAS }\end{array}$ & $\begin{array}{r}, 000 \\
1,000\end{array}$ & $\begin{array}{l}, 000 \\
, 000\end{array}$ & 1,000 & , & \\
\hline
\end{tabular}

a. Dependent Variable: DUPL

FONTE: Quadros elaborados através do SPSS. 
Dos relatórios acima, pode-se extrair as seguintes conclusões:

a) O valor estimado de duplicatas a receber em relação a vendas a prazo é $\hat{Y}=0+1 X$, ou seja, os valores da variável dependente (duplicatas a receber) será sempre igual a variação da variável independente (vendas a prazo);

b) os coeficientes de correlação e de espricicação são iguais a 1 , indicando uma perfeita relação entre as variáveis e $100 \%$ de explicação entre as variações; e

c) pode-se concluir que, possivelmente, não há simulação de valores a receber a título de duplicatas nas demonstrações financeiras da empresa.

Os resultados sugerem que todas as operações de vendas realizadas a prazo foram registradas contabilmente, já que as variáveis duplicatas a receber e vendas a prazo estão correlacionadas em grau máximo. É claro que isso, por si só, não constitui evidência de que a empresa não omitiu registro de saídas. Porém, essa coincidência não deixa de ser um indicador positivo. Com o apoio de alguns procedimentos adicionais, como a circularização, por exemplo, pode-se formar um juízo mais acurado sobre a validade dessas cifras. Se, pelo contrário, não se observasse uma correlação satisfatória entre as variáveis em questão, o auditor deveria colher explicações para as divergências ou até mesmo reforçar procedimentos para se certificar sobre a validade dos saldos.

\section{CONSIDERAÇÕES FINAIS}

Ultimamente, discute-se muito a respeito da eficácia dos trabalhos de auditoria, principalmente quando se lembra dos escândalos e fraudes que envolveram grandes empresas, como Banco Econômico, Banco do Nordeste, Banco Nacional e, mais recentemente, casos de repercussão internacional como Enron e WorldCom. Situações como essas parecem comprovar que os auditores atuam sob o risco de emitir parecer equivocado sobre as demonstrações contábeis examinadas, abalando seriamente a credibilidade da profissão. De fato, na literatura corrente, faz-se alusão de menos três categorias de risco a que fica exposto o serviço de auditoria: risco inerente; risco de controle; e risco de detecção, todos já definidos no corpo deste trabalho. Explorar recursos da estatística para controlar riscos dessa natureza foi a principal contribuição dessa pesquisa, cujo objetivo principal foi despertar a comunidade acadêmica e os profissionais da área para a conveniência de ampliar o uso de técnicas estatísticas em procedimentos de auditoria.

Valendo-se de recursos relativamente simples, como análise de regressão, conseguiu-se demonstrar que o uso de ferramentas estatísticas de fato pode ajudar o auditor a levantar indícios de erros e fraudes nas demonstrações contábeis. Quando se constatou, por exemplo, a falta de relacionamento significativo entre as variáveis estoques e desembolsos de caixa, gerou-se uma oportunidade de reflexão sobre as origens dos recursos utilizados para viabilizar a aquisição de mercadorias destinadas à comercialização. Como citamos anteriormente, essa é uma situação que pode induzir o auditor a levantar a hipótese de que a empresa lança mão de recursos não registrados contabilmente para honrar obrigações que mantém com fornecedores. De igual forma, pode-se levantar a hipótese de que a empresa se vale de recursos que deixaram de transitar contabilmente pelo caixa para minimizar custos tributários. Como se observa, a estatística pode contribuir para gerar informações relevantes em todas as fases do processo de investigação.

Por outro lado, os resultados também sugerem a ausência de problemas significativos na área de duplicatas a receber, já que demonstraram perfeita correlação 
entre a referida conta e vendas a prazo. Embora não se possa afirmar, a priori, que realmente a empresa registrou todas as vendas a prazo em sua contabilidade, essa constatação não deixa de ser um elemento importante para o trabalho de auditoria. Em tais circunstâncias, o auditor pode selecionar procedimentos mais adequados à formação de sua opinião sobre a validade dos saldos considerados e descartar outros que poderiam ser mobilizados na ausência dessa informação. Por exemplo, em vez de cotejar cada conta individualmente, ele pode partir diretamente para um procedimento de confirmação com os principais clientes da empresa, a fim de obter as evidências necessárias. Na hipótese contrária, certamente o auditor deveria considerar a necessidade de ampliar o escopo de seu trabalho até obter explicações suficientes para eventuais divergências.

Como se observa, os resultados alcançados vêm comprovar que o uso de ferramentas estatísticas pode contribuir, positivamente, na identificação de erros e fraudes associados às demonstrações contábeis examinadas pelos auditores, além de aumentar a segurança e a confiabilidade do trabalho, podendo até ajudar a reduzir os custos com os serviços de auditoria, uma vez que viabiliza a identificação dos pontos mais vulneráveis. Assim, a auditoria pode se tornar mais seletiva, priorizando contas e transações que, efetivamente, apresentem maior potencial de risco. Pode-se afirmar, portanto, que o uso de certas ferramentas estatísticas realmente agrega valor à auditoria e vem contribuir para minimizar riscos de se emitir uma opinião inadequada sobre as demonstrações contábeis. A análise de regressão e correlação é uma delas, como ficou comprovado. Contudo, principalmente por se tratar de estudo de caso, sugere-se realizar estudos adicionais para identificar, com maior amplitude, o uso de ferramentas desse tipo.

\section{REFERÊNCIAS}

DAVID, R. Anderson, DENNIS, J. Sweeney, THOMAS A. Williams., Estatística aplicada à administração e Economia(tradução da $2^{a}$ edição norte-americana). São Paulo: Afiliada, 2002.

BOYNTON, William C., JOHNSON, Raymond N. e KELL, Walter G. Tradução de Evaristo dos Santos. Auditoria. São Paulo, Editora Atlas S.A, 2002.

CONSELHO FEDERAL DE CONTABILIDADE. Resolução n 607/85.

CONSELHO FEDERAL DE CONTABILIDADE. Resolução n 1012/05.

FAMÁ, E. F.; JENSEN, M.C. Agency problems and residual claims. Journal of Law \& Economics. V. 26. EUA, june, 1983.

FRANCIS, Jere R. The British Accounting Review. Kidlington: Dec 2004. Vol. 36, $\mathrm{n}^{\circ}$. 4;

GIL, Antonio de Loureiro. Auditoria Operacional e de Gestão: Qualidade da Auditoria. São Paulo, Editora Atlas, 1996.

IBRACON. Normas e Procedimentos de Auditoria. 1992.

JENSEN, M.C. Divisonal performance measurement. Social Science Research Network (SSRN) Eletronic Library. EUA, 1998.

MAGALHÃES, Antonio de Deus F; LUNKES, Irtes Cristina; MULLER, Aderbal Nicolas. Auditoria das Organizações: Metodologias Alternativas ao Planejamento e à Operacionalização dos Métodos e das Técnicas. São Paulo, Editora Atlas, 2001.

MAS, José Ademir Dal. Auditoria Independente: Treinamento de Pessoal e Introdução aos Procedimentos de Auditoria. São Paulo: Editora Atlas, 2000. 
PETTERSON, Mark. The Journal of Corporate Accounting \& Finance. Hoboken: Jul/Aug 2005. Vol. 16, $\mathrm{n}^{\circ}$ 5;

PESQUEUX, Yvon. Critical Perspectives on Accounting. London: Aug 2005.Vol.16, nº 6.

STEVENSON, William J. Estatística Aplicada à Administração. Editora Harper \& Row do Brasil ltda, 1986.

VORHIE, Richard. Nonlitigation Risk and Pricing Audit Services. Auditing. Sarasota: May, 2005. Vol. 24, Num. 1;

VERGARA, Sylvia Constant. Projetos e relatórios de pesquisa em Administração. 2. ed. São Paulo: Atlas, 1998.

YIN, Robert K. Estudo de caso: planejamento e métodos. Tradução de Daniel Grassi. São Paulo, ed. Bookman, 2001.

\section{ENDEREÇO DOS AUTORES}

Faculdade de Tecnologia e Ciências

R. Artêmia P Freitas, S/N - SIM

Feira de Santana, BA - Brasil

44115-000
Universidade Federal da Bahia

Faculdade de Ciências Contábeis

Praça 13 de maio, $n^{\circ} 06$ - Piedade

Salvador, BA - Brasil

40070-010 